\title{
A Discourse Analysis of the Language Use in Courts During Trials
}

\author{
* Kanza Javed, Assistant Professor / PhD Scholar (Corresponding author) \\ ** Prof. Dr. Mamuna Ghani, Former Dean
}

\begin{abstract}
It is a common phenomenon that every case that is pursued by the advocate is due to the use of powerful language and explains, proves, give statements, and enlighten the matter in the most appropriate way to get the attention of the whole body. Therefore, in present, the era it has become the hot topic of discussion among legal writers to focus on the effects of variations in the presentational style of the witnesses during court-trails. Thus, keeping in view the above-mentioned facts, this study was planned to examine the pros and cons of the language used in courts during trials in various suburbs of the Punjab, Pakistan. Focusing on the paradigm of research, this study was quantitative. A total of 150 participants belonging to the law fraternity took part in the study to find out whether language plays a significant role during court-trails, of which almost half of them gave their response in the affirmative. Therefore, it can be concluded that this study will also help take suitable measures for enhancing the quality of the effective language of presentation during court trials.
\end{abstract}

Keywords: Effective Language, Presentational Style, Court-trials, Suburbs, Law Fraternity. Introduction

All the special attention that the law has attained today is due to the use of language. No legal notions exist outside language. According to one critic, 'It is on the loom of language that all law is spun (Weeramantry, 1975). During the court trials, advocates and witnesses use different languages according to their convenience and explain the matter in the best way. However, it is a common phenomenon that every case that is pursued by the advocate is capable of using powerful language and explains, proves, gives the statements, and enlightens the matter in the most appropriate way to get the attention of the whole body. Furthermore, effective language is the basic attribute of every jurist to decide, punish, favor, and forgive as the decision of every subject matter (Goddard, 1996). Therefore, in the present era, it has become a hot topic of discussion among legal writers to learn the impacts of the usage of effective language during court-trials. Thus, keeping in view the abovementioned facts, this study explains the impact of language used during the court trials in Pakistan.

\section{Literature Review}

'Law is codified and mediated through language'. This statement means that everything that is depicted in law has to be always interpreted through language. But it should not be believed that there is no Law without language as is the case of customary law, where the law is not expressed in words but situations. No doubt, everyday language is quite different from the language of the law, that's why; the language of the law cannot be used for daily practice (Saxton, 1998). For this reason, the legal language is usually reviewed by forensic linguists who tend to apply the knowledge of linguistic theory accurately to the Forensic context of the law.

The use of language in court has a profound impact on the legal system. Initially, the system was called a 'gladiatorial' where the parties to the dispute faced challenging accounts before an unbiased umpire (Laster, 1990). It faces through language, and 'truth' is eventually the creation of the communication between defense and trial. Lambert in his study revealed that it is possible to differentiate between different speech styles as well as to relate these speech styles to social contexts and social settings of the speakers' in a wide variety of situations.' However, in non-legal contexts, studies have revealed that acceptance of arguments by another person is greatly influenced by a speaker's speaking style.

\footnotetext{
* The Islamia University of Bahawalpur, Pakistan Email: kanza javaid88@yahoo.com

** Faculty of Arts \& Languages, The Islamia University of Bahawalpur, Pakistan

Email: drghani2009@yahoo.com
} 
The language of the courtroom has been widely studied by forensic linguists, which means that simplifications and exclusions are unavoidable. It is worth mentioning that extensive research in this field is related to identifying and proposing successful communication strategies in court. For example, this is a training manual that focuses on the most appropriate promotional techniques ('howto' books) and is often based on the experience of legal scholars. It can be seen that the application of these theoretical principles and recommendations may be very different in the actual environment. Although the indoor court language can be considered a relatively standard communication procedure, every moment of the dialogue involves a certain degree of changeability.

Another sequence of studies during mock court-trials mostly concentrated on the analysis of jury behavior and jury decisions. The experiments described above can provide important insights into understanding the dynamics of different courts. However, problems associated with the environmental validity of jury impressions are often raised. Each case is so inherently connected and context-dependent that the room may not make mock disclosures to investigate the actual events of the court conversation. In particular, important issues are related to the representation of the jurors, the setting of the study, and the test medium (Merry, 1990).

An additional broad area of research that is mainly significant to the context of this work is constructed on the interpretation, investigation, and description of actual court procedures. Given the intricacy of trial communications, it is not possible to obtain complete and accurate scores, particularly when one thinks that various studies often contain diverse trends. Indoor courts are based on some key areas that can be identified in language learning, such as talk, conversation, criticism, or a corpus-based approach. (Conley et al, 1979).

In 'Conversational Research,' we can cite the excellent work of Aldridge (2010) which shows insight on indoor court changes, motivation, and research. Other studies have focused specifically on the process of conducting inspections and the development of questionnaires (Harris, 1984). Special attention was also paid to this area, especially in the analysis of testimony styles (Danet, 1980).

Research on the language of proceedings often confirms that courts represent important cultural venues in which the power of social forces comes into play. Moreover, the study of legal dialogue is seen not only as an opportunity to study captivating linguistic occurrences but also as an understanding of how legal speech is linked to social dynamics and how it is also investigating legal discourse, production, interpretation, or common influence of the construction in which participants must face important consequences. It is safe to say that this supposition applies to all kinds of discourse, but the role of legal discourse cannot be denied. Indeed, it is possible to pass and exercise power in legal discourse.

As mentioned earlier, another important area of study in forensic linguistics is the presentation of expert linguists as skilled witnesses. Finally, it is worth noting that corpus-based research has also fascinated substantial concern in the latest years (Heffer, 2005).

\section{Research Methodology \\ Paradigm of Study}

A quantitative method was applied in all procedures, from acquiring the raw data to analyze it and deducing meaningful outcomes. A self-constructed questionnaire was used to collect data and later analyzed.

\section{Sampling and Participants}

For the present study, 150 participants including judges and lawyers having 10 years of field experience after completing their LLB program between age group 26-35 years from urban areas of Punjab, Pakistan were selected randomly to take part in this study. They were required to give their views regarding statements stated in questionnaires.

\section{Data Collection}

For the quantitative study, a five-point Likert scale questionnaire having 15 items was used. The Likert scale and questionnaire were adopted from the article 'The Power of Language: Presentational Style in the Courtroom' written by John M. Conley, William M. O'Barr, and E. Allan Lind (1976) and modified according to my study. All items of the questionnaire included close-ended options.

\section{Research Design}

For data collection and appropriate information regarding my research plan, I had proposed a comprehensive study to highlight the discourse analysis of the language used in courts during trials in Pakistan. After the data collection in questionnaire form, it was converted into a numeric form for the 
preparation of graphs and implication of statistical analysis. After collecting the data from the participants, it has been analyzed through SPSS.

\section{Data Analysis}

The graphical representation of the questionnaire filled by the participants and their response is as follows:

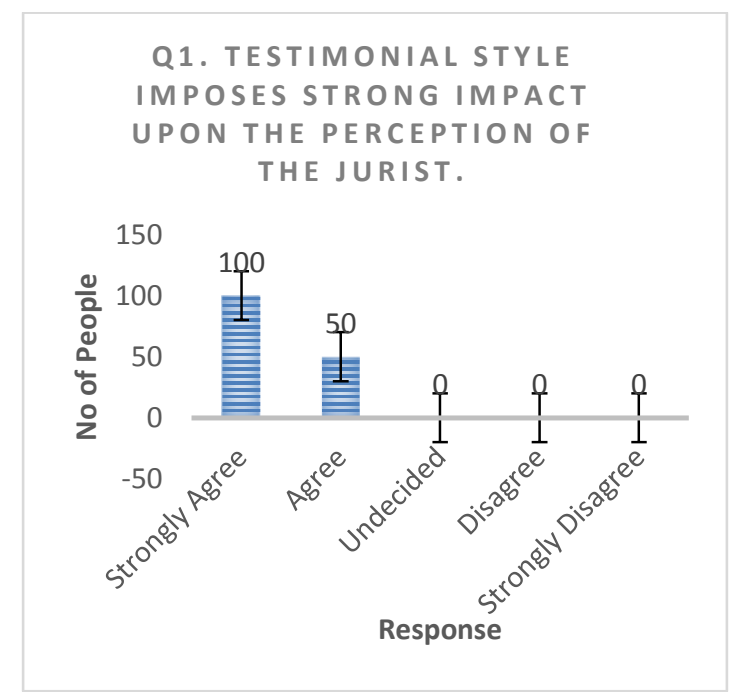

$\underline{\text { Graph \# } 1}$

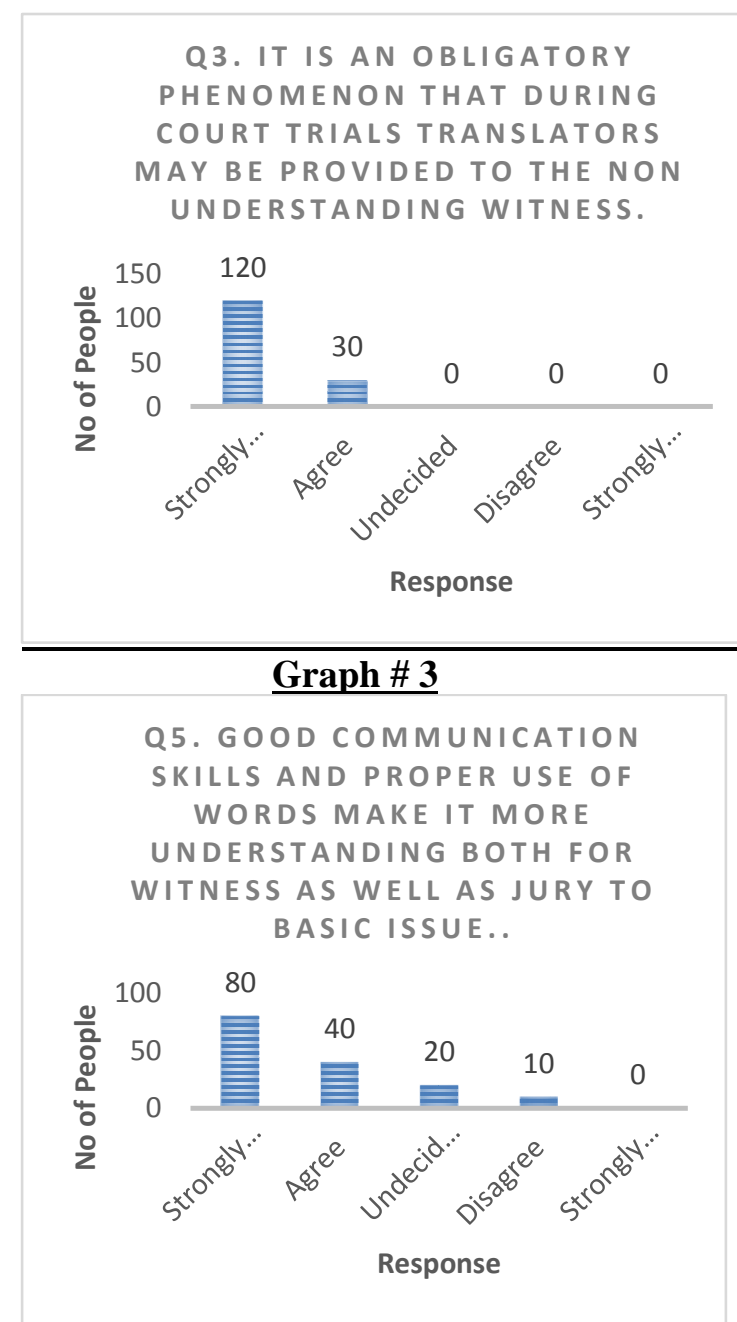

$\underline{\text { Graph \# } 5}$

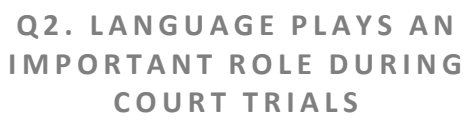

Q2. LANGUAGE PLAYS AN

IMPORTANT ROLE DURING COURT TRIALS

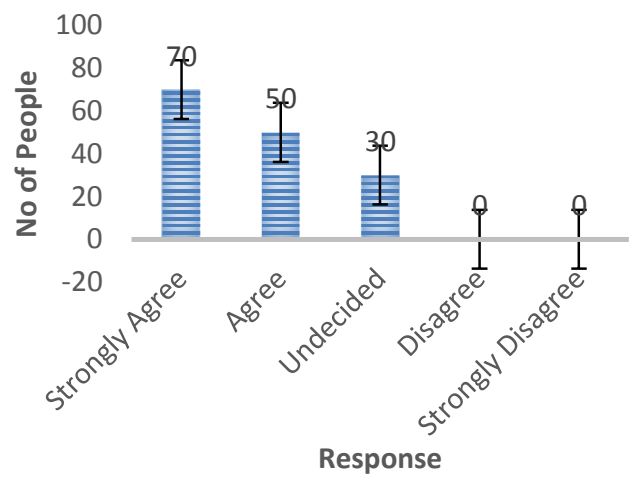

Graph \# 2

Q4. SENSITIVITY TO

LANGUAGE VARIATIONS

MIGHT BE INCORPORATED

INTO THE LAW OF EVIDENCE ITSELF.

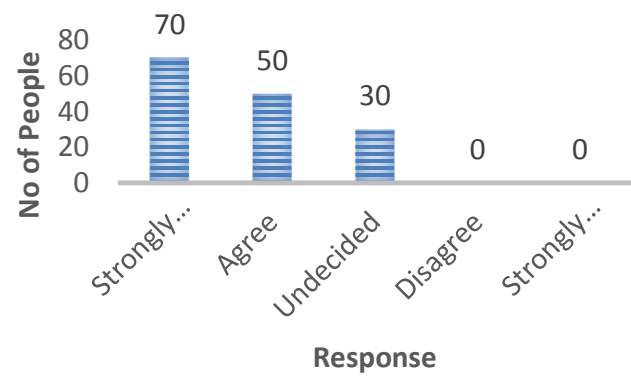




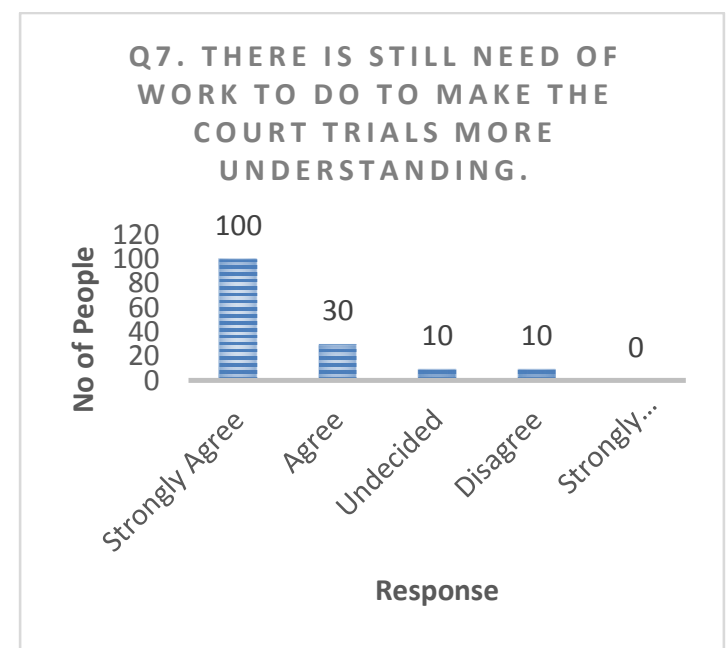

Graph \# 7

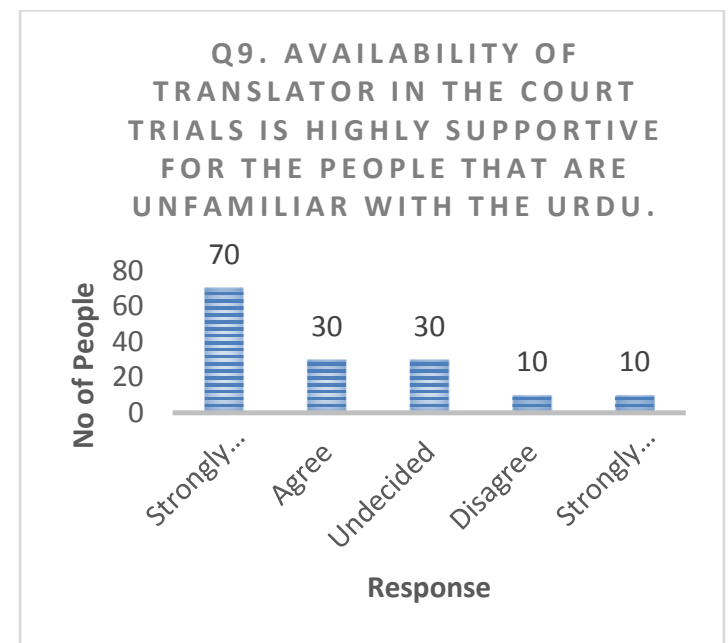

Graph \# 9

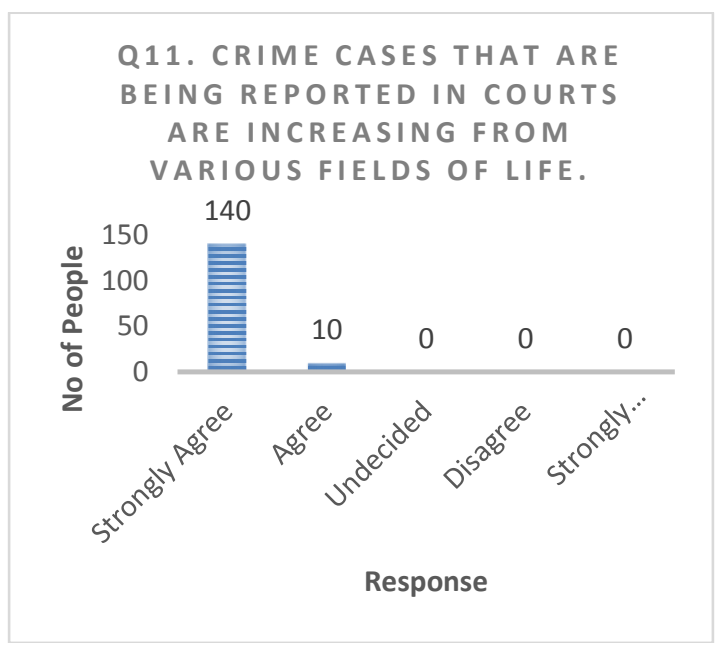

Graph \# 11
Q8. PEOPLE THAT BELONG TO

BACKWARD AREAS WHO ARE

UNABLE TO UNDERSTAND THE

URDU AND ENGLISH FEEL

EMBARRASSED DURING COURT TRIALS.

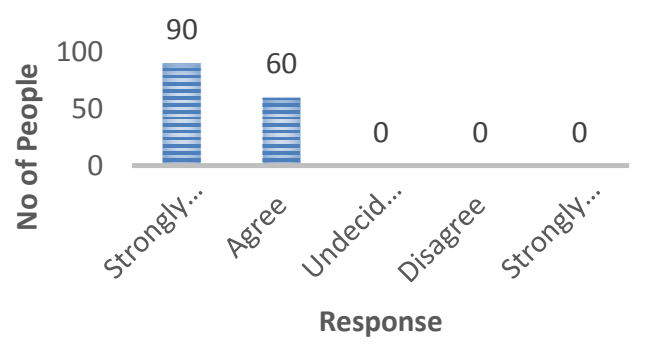

$\underline{\text { Graph\# } 8}$

Q10. TECHNICAL LANGUAGE

THAT IS BEING IN USE DURING COURT TRIALS IS VERY COMPLEX AND COMMON PEOPLE TAKE MUCH TIME TO UNDERSTAND IT.

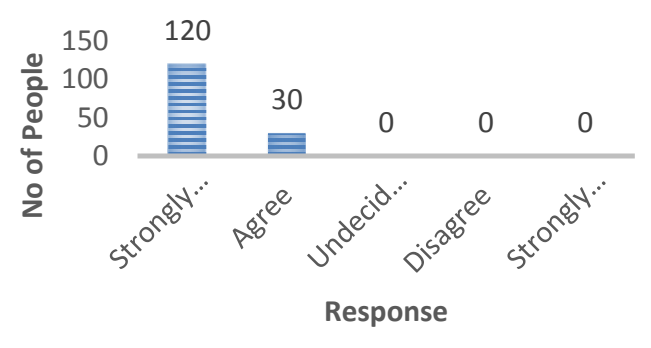

$\underline{\text { Graph \# } 10}$
Q12. TESTIMONIAL STYLE OF WITNESS INCREASE THE WORTH OF THEIR STATEMENTS.

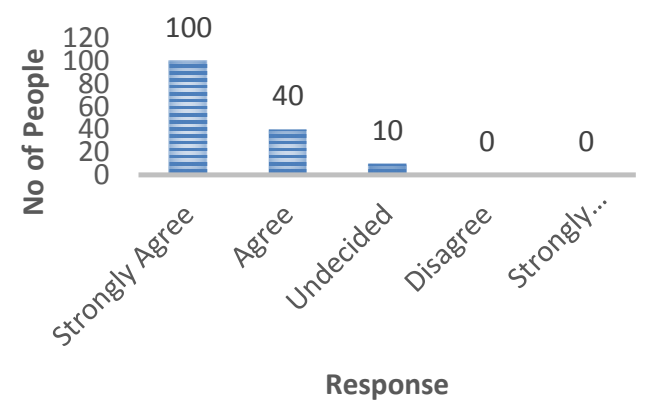

Graph \# 12 
Q13. DURING COURT TRIALS

PRESENTING STYLE IMPOSE

STRONG IMPACT ABOUT THE

DECISION MAKING POWER OF THE JURISTS.

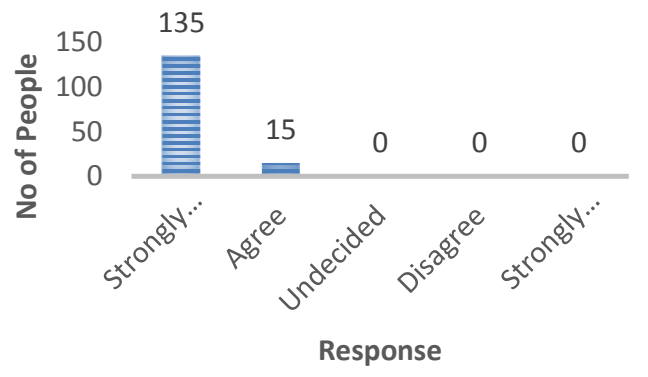

$\underline{\text { Graph\# } 13}$

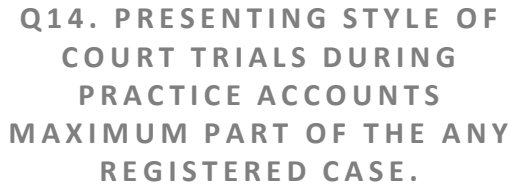

Q14. PRESENTING STYLE OF COURT TRIALS DURING

PRACTICE ACCOUNTS MAXIMUM PART OF THE ANY REGISTERED CASE.

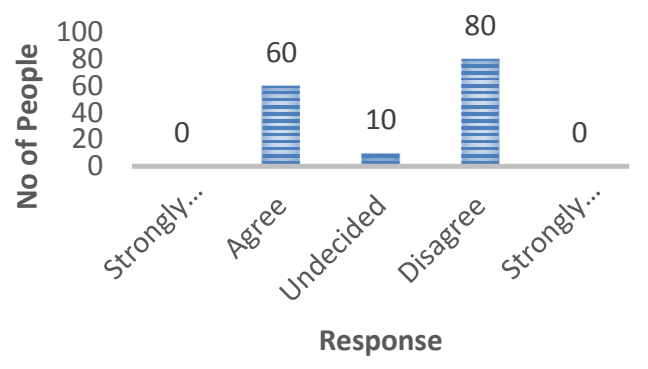

$\underline{\text { Graph \# } 14}$

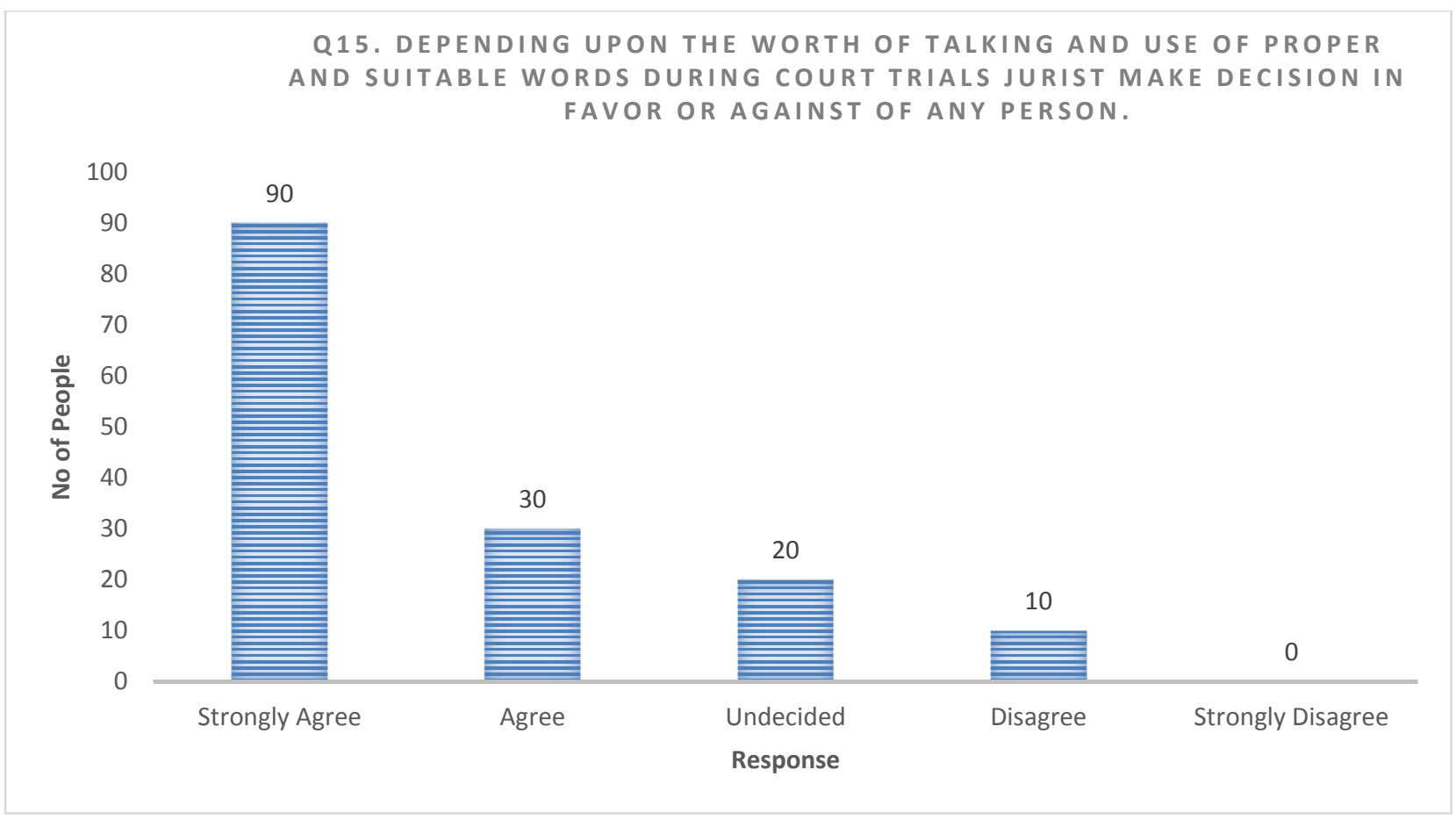

Graph \# 15 


\section{Results and Discussion}

From the total 150 participants, 70 participants strongly agreed, 50 participants agreed while 30 participants remained undecided when they were asked about do you think that language is an important aspect of court trials.

Similarly, 100 participants strongly agreed while 50 participants agreed to the view that testimonial style imposes a strong impact upon the perception of the jurist.

Extending our survey, 120 participants strongly agreed while 30 participants agreed to the statement that it is an obligatory phenomenon that during court trials translators may be provided to the non-understanding witness.

Moreover, 70 participants strongly agreed, 50 participants agreed while 30 participants show undecided response to sensitivity to language variations might be incorporated into the law of evidence.

Also, 80 participants strongly agreed, 40 participants agreed, 20 participants remain undecided while 10 participants disagreed with the statement that good communication skills and proper use of words make it more understanding both for witness as well as jury to the basic issue.

Following the same footsteps, 110 participants strongly agreed, 30 participants agreed and 10 participants show undecided attitude towards the question that use of the testimonial style makes it feasible for everyone to understand the substance.

Similarly, 100 participants strongly agreed, 30 participants agreed, 10 participants remain undecided while 10 participants disagreed with the statement that there is still a need for work to do to make the court trials more understanding.

Furthermore, 90 participants strongly agreed while 60 participants agreed with the concern that People that belong to backward areas who are unable to understand Urdu and English feel embarrassed during court trials.

Additionally, 70 participants strongly agreed, 30 participants agreed, 30 participants remain undecided while 10 participants disagreed with the statement that the Availability of a translator in court trials is highly supportive for people that are unfamiliar with Urdu.

Moreover, 120 participants strongly agreed while 30 participants agreed with the statement that Technical language that is being in use during court trials is very complex, and common people take much time to understand it.

Similarly, 140 participants strongly agreed while 10 participants agreed with the proclamation that Crime cases that are being reported in courts are increasing from various fields of life.

100 participants strongly agreed, 40 participants agreed and 10 participants remain undecided about the statement that during court trials presenting style imposes a strong impact on the decisionmaking power of the jurists.

However, 135 participants strongly agreed while 15 participants agreed about the presenting style of court trials during practice accounts maximum part of any registered case.

Furthermore, 60 participants agreed, 10 participants remain undecided while 80 participants disagreed with the statement that depending upon the worth of talking and use of proper and suitable words during court trials jurists make a decision in favor or against any person.

Results obtained after the detailed analysis show that effective language plays a significant role during court trials. Moreover, it is also observed that during the court trial, people come from various parts of the country and use different languages that vary from person to person. Sometimes, it becomes difficult to understand the proper meaning of the statement that a person uses while acting as the witness in a case presented to the court. Similarly, few people are unable to understand the proceedings of the court due to the use of technical language and style. Therefore, it is an obligatory duty of the court to respond to purely linguistic problems in determining the form of speech.

\section{Conclusion}

Based on the analysis of data, it is found that language plays a significant role during court-trials as well as imposes a strong impact on the perception of jurists. As effective language is the basic attribute of every jurist to decide to punish, favor and forgive as the decision of every subject matter, so, sensitivity to language variation should be incorporated into the law of evidence and translators should be provided to non-understanding witnesses.

Therefore, it can be concluded that this study will help find out the existing court functioning and impact of effective language during court proceedings. This study would also help take suitable 
measures for enhancing the quality of effective language in courts in Pakistan, resulting, increasing the efficiency of the court trials. Additionally, this study is also significant because it has not only presented a holistic picture of effective language during court-trials but also identified its strengths and shortcomings

\section{Limitations of Study}

The current study has certain limitations.

The participants having 10 years of field-experience took part in this study.

This research is restricted to urban areas of the province Punjab, Pakistan.

Being a female, the researcher has limited herself to the province of Punjab in Pakistan.

The study was narrowed to its design, technique, measuring devices, and statistical methods.

\section{Acknowledgment}

This research paper has been extracted from the Ph.D. thesis titled "The Power of Language: A Study of Presentational Style in Court-room Practices in Pakistan" by Ms. Kanza Javed (Assistant Professor/Ph.D. Scholar, The Islamia University of Bahawalpur), supervised by Prof. Dr. Mamuna Ghani (Former Dean, Faculty of Arts \& Languages, The Islamia University of Bahawalpur) and has been published in the partial fulfillment of the requirement for the degree of Doctor of Philosophy in English Linguistics from Department of English, The Islamia University of Bahawalpur Pakistan.

\section{References}

Aldridge, M., (2010). Vulnerable Witnesses in the Criminal Justice System. In: M. Coulthard and A. Johnson, Eds. The Routledge Handbook of Forensic Linguistics. New York: Routledge, pp. 296-314.

Berk-Seligson, S., (2002). The Bilingual Courtroom: Court Interpreters in the Judicial Process. Chicago: University of Chicago Press.

Weeramantry. C.G., (1975). Law in Crisis: Bridges of Understanding Hardcover. Capemoss.

Conley, John \& O Barr, William \& Lind, E., (1979). The Power of Language: Presentational Style in the Courtroom. Duke Law Journal.

Danet, B., (1980). Language in the Legal Process. Law \& Society Review.

Goddard, C., 1996. Can Linguists Help Judges Know What They Mean? Linguistic Semantics in the Courtroom. Forensic Linguistics, no. 3, pp. 250-272.

Hale, S., (2002). How Faithfully Do Court Interpreters Render the Style of non-English Speaking Witnesses' Testimonies? A Data-based Study of Spanish-English Bilingual Proceedings. Discourse Studies, no. 4 (1), pp. 25-47. http://dx.doi.org/10.1177/14614456020040010201

Harris, S., (1984). Questions as a Mode of Control in Magistrates' Courts. International Journal of the Sociology of Language, no. 49, pp. 5-27.

Laster, K., (1990). Legal Interpreters: Conduits to Social Justice? Journal of Intercultural Studies, no. 11 (2), pp. 15-32. http://dx.doi.org/10.1080/07256868.1990.9963364

Levi, J. N., (1993). Evaluating Jury Comprehension of Illinois Capital-sentencing Instructions. American Speech, no. 68 (1), pp. 20-49. http://dx.doi.org/10.2307/455834

McMenamin, G., (2010). Forensic Stylistics. Theory and Practice of Forensic Stylistics. In: M. Coulthard and A. Johnson, Eds. The Routledge Handbook of Forensic Linguistics. New York: Routledge, pp. 487-507.

Merry, Sally Engle., (1990). Getting Justice \& getting Even: legal consciousness among workingclass Americans, Chicago. The University of Chicago Press.

Redlich, A. D., (2007). Double Jeopardy in the Interrogation Room for Youths with Mental Illness. American Psychologist, no. 62 (6), pp. 609-611. http://dx.doi.org/10.1037/0003066X62.6.609

Saxton, B., (1998). How Well Do Jurors Understand Jury Instructions - A Field Test Using Real Juries and Real Trials in Wyoming? Land and Water Law Review, no. 33, pp. 59-121.

Shuy, R. W., (1993). Language Crimes: The Use and Abuse of Language Evidence in the Courtroom. Oxford: Blackwell.

Shuy, R. W., (2001). DARE's Role in Linguistic Profiling. DARE Newsletter, no. 4 (3), pp. 1-5.

Tiersma, P. M., (1999). Legal Language. Chicago: University of Chicago Press.

Tiersma, P. M., (2010). Instructions to Jurors. Redrafting California's Jury Instructions. In: M. Coulthard and A. Johnson, Eds. The Routledge Handbook of Forensic Linguistics. New York: Routledge, pp. 251-264. 